\title{
FACTORIAL STRUCTURE OF ROSENBERG'S SELF-ESTEEM SCALE AMONG INJURED MALE RUGBY PLAYERS IN THE KENYA CUP COMPETITION
}

\author{
Anthony Muchirii, \\ Edwin K. Wamukoya', \\ Donald Kokonya ${ }^{2}$ \\ ${ }^{1}$ Department of Health Promotion and Sport Science, \\ School of Public Health, Biomedical Sciences and Technology, \\ Masinde Muliro University of Science and Technology, \\ Kakamega, Kenya \\ 2Department of Psychiatry, \\ School of Medicine, \\ Masinde Muliro University of Science and Technology, \\ Kakamega, Kenya
}

\begin{abstract}
:
Four different confirmatory factor analysis (CFA) models, including CFAs with correlated traits, uniqueness's, and methods, were employed to test the factorial structure of Rosenberg's (1965) self-esteem scale in a sample of injured male rugby players in the Kenya cup competition. The outcome of the factorial analysis to some extent concurs with studies conducted earlier. These finding depict that (a) there exists a single global selfesteem factor underlying responses to Rosenberg scale; (b) method effects associated with item wording exist; and (c) the method effects were associated primarily with positively, rather than negatively, worded items. The sample consisted of 105 injured male rugby players the average age was $21.7 \pm 5.3$ years, and the majority $23.8 \%$ were 20 years old. Majority $67.6 \%(n=71)$ of the respondents were forwards, while $32.4 \%(n=34)$ were backs. $82.9 \%$ were not capped with the national team while $11.4 \%(n=12)$ weighed $70 \mathrm{kgs}$. The research hypothesized a four-factor structure of the RSES utilizing CFA with the SPSSAMOS 16. The first model outcome was, $\left(X^{2}=132.2 \mathrm{df}=35 \mathrm{CFI}=0.561 \mathrm{NFI}=0.463\right.$ RMSEA=0.163 SRMR=0.1373 AIC=192.2. The second model $\left(X^{2}=77.609 \mathrm{df}=27 \mathrm{CFI}=0.748\right.$ $\mathrm{NFI}=0.685$ RMSEA $=0.134 \mathrm{SRMR}=0.1197 \mathrm{AIC}=153.609)$. The third model was a Unidimensional positive wording $X^{2}=58.378 \mathrm{df}=25 \mathrm{CFI}=0.834 \mathrm{NFI}=0.763$ RMSEA $=0.113$ SRMR=0.0888 AIC $=138.378$. Finally, a model was run on Positive and Negative wording correlated, the outcomes $\left(X^{2}=79.68 \quad \mathrm{df}=34 \quad \mathrm{CFI}=0.748 \quad \mathrm{NFI}=0.685 \quad\right.$ RMSEA $=0.114$ $\mathrm{SRMR}=0.1151 \mathrm{AIC}=121.68$ ). Every model, including the single-factor model (Model 1), fits
\end{abstract}

i Correspondence: email muchiri.antony.am@gmail.com 
data adequately. However, the function of a single theoretical dimension (GSE) was contaminated by method effects. Our results show that method effects need to be taken into account to obtain a close model fit (i.e., RMSEA < 0.05 ).

Keywords: self-esteem, rugby players, model, structural equation modelling, Kenya Cup

\section{Introduction}

Research in sports psychology suggests that self-esteem is a significant and essential aspect of personal identity which can assist in influencing the athlete behaviour and outcomes especially after the occurrence of injuries. help shape a host of human behaviors (Marsh, 1993; Mruk, 1999; Pelham \& Swann, 1989). Sports Injuries emerge from various factors influencing various parts of the body. Various parts of a game may cause these exertions, e.g., Tackle stage, scrum, destroys, and rucks. The seriousness of the injury is consistently differing between sportspersons; hence, there can be a few ways to deal with outcomes of the Injuries. Much of the time, treatment depends fair and square of injury and the mix of psychosocial and physical components (Mero, 2007). Persons with high self-esteem have been characterized as possessing self-respect and self-worth, whereas those people with low self-esteem are thought not to respect themselves, feel worthy, adequate, or otherwise efficient (Rosenberg, 1979). Higher levels of self-esteem have also been correlated with better psychological well-being (Rosenberg, Schoenbach, Schooler, \& Rosenberg, 1995).

In the study of sports character and sports support, the utilization of the mixed methods to deal with outcomes of sports injuries has been alluded as a basic issue which has an effect on self-esteem. (Lundberg, Taniguchi, McCormick and Tibbs, 2011). This is because of individual and social perspectives, which can shift a great deal starting with one setting. Individual objectives and dealing with various circumstances at various occasions/circumstances or during training which in turn affects self-esteem and, which will influence Orientation to injury and recuperation from injury. Direction to injury and recuperation from injury straightforwardly identifies with social foundations, comprising of nearby guidelines of a competitor and how he has been instructed to act in different circumstances. At the point when all these social, moral, and different issues are joined, the consequence of a competitor to deal with a physical issue, originating from various foundation, might be hard to comprehend to other people (Patrick, Cheung and Lydia, 2007).

\section{Data \& Statistical Procedures}

Standard statistical methods were used for the calculation of the means \pm standard deviation (SD). Statistical analysis was performed using SPSS v 25. The level of significance was set at $\mathrm{p}<0.05$, and data are reported as means and $95 \%$ confidence intervals (CI). 
The sample consisted of 105 injured male rugby players the average age was $21.7 \pm 5.3$ years, and the majority $23.8 \%$ were 20 years old. Majority $67.6 \%(n=71)$ of the respondents were forwards, while $32.4 \%(n=34)$ were backs. $82.9 \%$ were not capped with the national team while $11.4 \%(n=12)$ weighed $70 \mathrm{kgs}$. The mean experience for the respondents was $5.3810 \pm 3.052$ years. The mean weight of the respondents was $78.952 \pm 21.404$ years. On marital status, majority of the injured male rugby players $88.6 \%$ $(n=93)$ were single, while $11.4 \%(n=12)$ were married. The information was tested by found to be statistically significant following the test of goodness fit $(\chi 2=62.486, \mathrm{df}=1$, $\mathrm{P}<.0001)$.

The study also included various psychiatric measures-including Rosenberg's self-esteem scale. Questionnaires were administered by trained interviewers after participants completed informed consent forms. In the natural history study, Rosenberg's scale followed a SE1-SE10 sequence (see Appendix), and each of the 10 items was measured as a 4-point Likert scale ranging from 1 (strongly disagree) to 4 (strongly agree). As usual, the negative items were reversed-scored before any analyses were conducted.

\section{Results}

The research hypothesized a four-factor structure of the RSES utilizing CFA with the SPSS-AMOS 16. Self-esteem has been widely studied Psychological construct both in social and personal psychological research by psychologist almost from the beginning of the sports discipline (Tesser, 2013). Form our study of $\mathrm{N}=105$ the average score of 2.345 with a standard deviation of .876 with a satisfactory internal consistency of Cronbach alpha of 0.818 . if the items follow a multivariate ordinary dissemination (a prerequisite, which is hard to satisfy in viable circumstances and was rarely tried in RSES approval examines). For motivations behind examination as applied by different investigations, the accompanying measurements and limit esteems were utilized to assess model fit: comparative fit index (CFI) 0.90, root mean square error of estimation (RMSEA) 0.10, and weighted root mean square residual (WRMR) 0.05, GFI >.95 is satisfactory). The model fit was determined whether items had a factor stacking 0.40 (Steiger, 2007; Yu, 2002).

Four models of hypothetical structure of the scale were estimated. The first model represented the original one-dimensional structure of the RSES with all the structure of the Global self-esteem (GLO). The confirmatory factor analysis was carried out using AMOS 16 Software and satisfactory single-sample model-fit was represented above all by the conventional values of CFI and NNFI $>.95$, and RMSEA $<.06$. the models were estimated on the basis of covariance matrix between items of Maximum Likelihood Method for continuous data. The conventional fit indices were used to evaluate the models' fit (Urbanek, 2000) chi-squares and degrees of freedom, comparative fit index (CFI), Non named Fit Index (NFI). Root mean Square of Approximation (RMSEA) 90\% confidence intervals and Akaike Information criterion (AIC). The following table 1 shows the outcomes on the four models. 
Anthony Muchiri, Edwin K. Wamukoya, Donald Kokonya

FACTORIAL STRUCTURE OF ROSENBERG'S SELF-ESTEEM SCALE

AMONG INJURED MALE RUGBY PLAYERS IN THE KENYA CUP COMPETITION

\begin{tabular}{|l|c|c|c|c|c|c|}
\hline \multicolumn{7}{|c}{ Table 1: FIT indices of estimated models } \\
\hline & $\begin{array}{c}\text { Chi-squares } \\
\text { (degree of freedom) }\end{array}$ & CFI & NFI & $\begin{array}{c}\text { RMSEA 90\% } \\
\text { Confidence interval }\end{array}$ & SRMR & AIC \\
\hline $\begin{array}{l}\text { Uni-dimensional } \\
\text { uncorrelated }\end{array}$ & $132.2(35)$ & 0.561 & 0.463 & $.134-.194$ & 0.1373 & 192.2 \\
\hline $\begin{array}{l}\text { Uni-dimensional } \\
\text { negative wording }\end{array}$ & $77.609(27)$ & 0.748 & 0.685 & $.100-.170$ & 0.1197 & 153.609 \\
\hline $\begin{array}{l}\text { Uni-dimensional } \\
\text { positive wording }\end{array}$ & $58.378(25)$ & 0.834 & 0.763 & $.76-.151$ & 0.0888 & 138.378 \\
\hline $\begin{array}{l}\text { Positive and } \\
\text { negative wording correlated }\end{array}$ & $79.680(34)$ & 0.773 & 0.676 & $0.81-0.146$ & 0.1151 & 121.68 \\
\hline
\end{tabular}

The first model was unidimensional hypothesized to the global self-esteem score (GLO). The following Figure 1 shows the model structure.

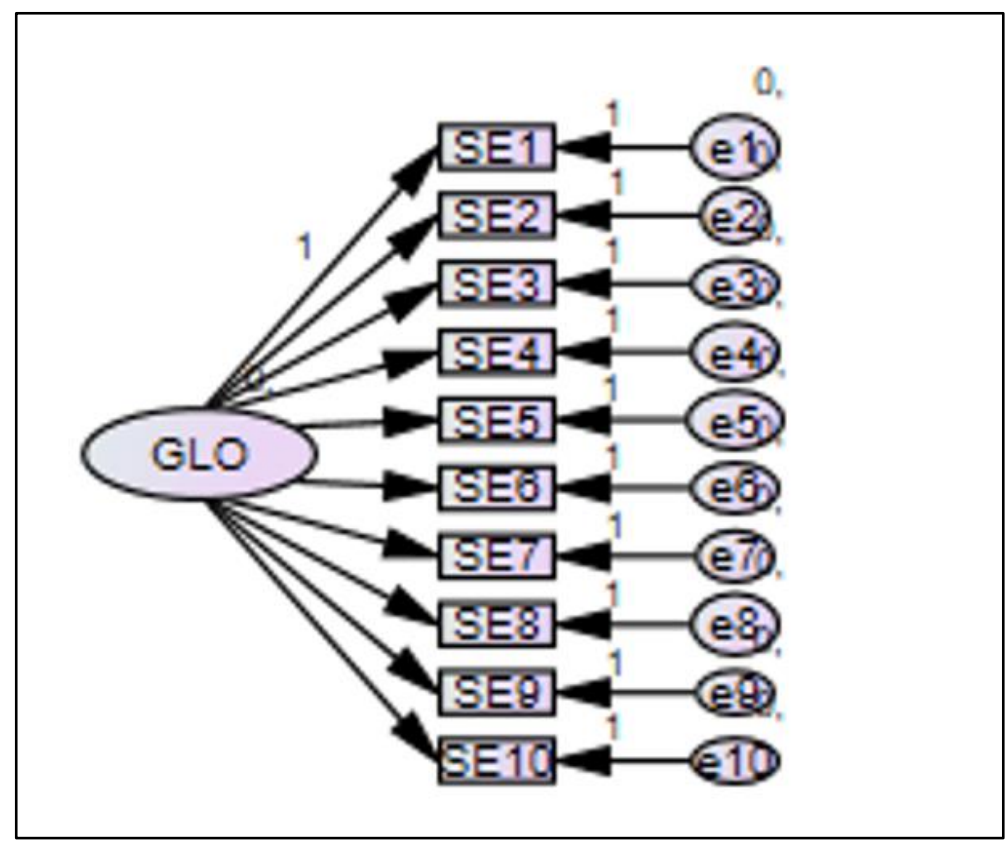

Figure 1: Uni-dimensional Uncorrelated RSES

Table 2: Regression Weights: (Group number 1 - Default model)

\begin{tabular}{|c|c|c|c|c|c|c|c|}
\hline & & & Estimate & S.E. & C.R. & P & Label \\
\hline SE1 & $<---$ & Pos & 1.000 & & & & \\
\hline SE3 & $<---$ & Pos & 1.178 & .245 & 4.803 & $* * *$ & \\
\hline SE4 & $<---$ & Pos & .723 & .182 & 3.965 & $* * *$ & \\
\hline SE7 & $<---$ & Pos & .637 & .180 & 3.536 & $* * *$ & \\
\hline SE10 & $<---$ & Pos & .202 & .174 & 1.160 & .246 & \\
\hline SE2 & $<---$ & Neg & 1.000 & & & & \\
\hline SE5 & $<---$ & Neg & -2.421 & .914 & -2.647 & .008 & \\
\hline SE6 & $<---$ & Neg & -4.377 & 1.546 & -2.832 & .005 & \\
\hline SE8 & $<---$ & Neg & -1.293 & .577 & -2.240 & .025 & \\
\hline SE9 & $<---$ & Neg & -2.680 & .946 & -2.833 & .005 & \\
\hline
\end{tabular}


Several observations are worth noting. First, the single-factor model had a relatively poor fit to these data using most existing conventions for interpreting model fit statistics $\left(X^{2}=132.2 \mathrm{df}=35 \mathrm{CFI}=0.561 \mathrm{NFI}=0.463\right.$ RMSEA=0.163 SRMR=0.1373 AIC=192.2) (e.g., comparative fit index [CFI] values above .95, root mean square error of approximation [RMSEA] values around .06, standardized root mean square residual [SRMR] values below .08; see Brown, 2006). The second model which was a hypothesized Unidimensional negative wording of the items in the RSES was done the following figure 2 illustrates the outcomes.

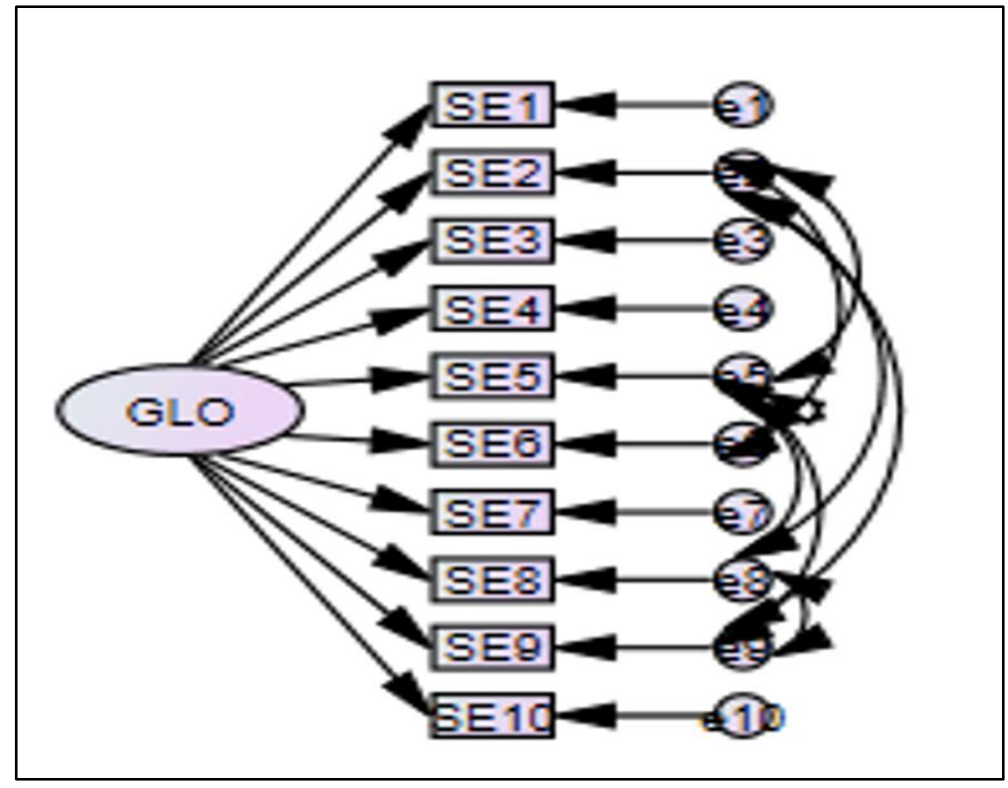

Figure 2: Uni-dimensional negative wording of RSES

Table 3: SEM outcomes of RSES

\begin{tabular}{|c|c|c|c|c|c|c|c|}
\hline & & & Estimate & S.E. & C.R. & P & Label \\
\hline SE1 & $<---$ & GLO & 1.000 & & & & \\
\hline SE2 & $<---$ & GLO & -.224 & .170 & -1.317 & .188 & \\
\hline SE3 & $<---$ & GLO & 1.061 & .190 & 5.600 & ${ }^{* * * *}$ & \\
\hline SE4 & $<---$ & GLO & .711 & .177 & 4.010 & $* * * *$ & \\
\hline SE5 & $<---$ & GLO & -.072 & .254 & -.282 & .778 & \\
\hline SE6 & $<---$ & GLO & .762 & .265 & 2.880 & .004 & \\
\hline SE7 & $<---$ & GLO & .610 & .175 & 3.483 & $* * *$ & \\
\hline SE8 & $<---$ & GLO & -.206 & .206 & -1.000 & .317 & \\
\hline SE9 & $<---$ & GLO & .863 & .230 & 3.758 & ${ }^{* * *}$ & \\
\hline SE10 & $<---$ & GLO & .203 & .170 & 1.197 & .231 & \\
\hline
\end{tabular}

The model depicts a poor model fit and a less good model compared to the first model. The chi-square values depict a correlation between the items of RSES (X2=77.609 $\mathrm{df}=27$ CFI=0.748 NFI=0.685 RMSEA=0.134 SRMR=0.1197 AIC=153.609).

The third model was a Uni-dimensional positive wording of RSES items that were asked, the model $(\mathrm{X} 2=58.378 \mathrm{df}=25 \mathrm{CFI}=0.834 \mathrm{NFI}=0.763 \mathrm{RMSEA}=0.113 \mathrm{SRMR}=0.0888$ AIC=138.378). the following figure 3 shows the model. 


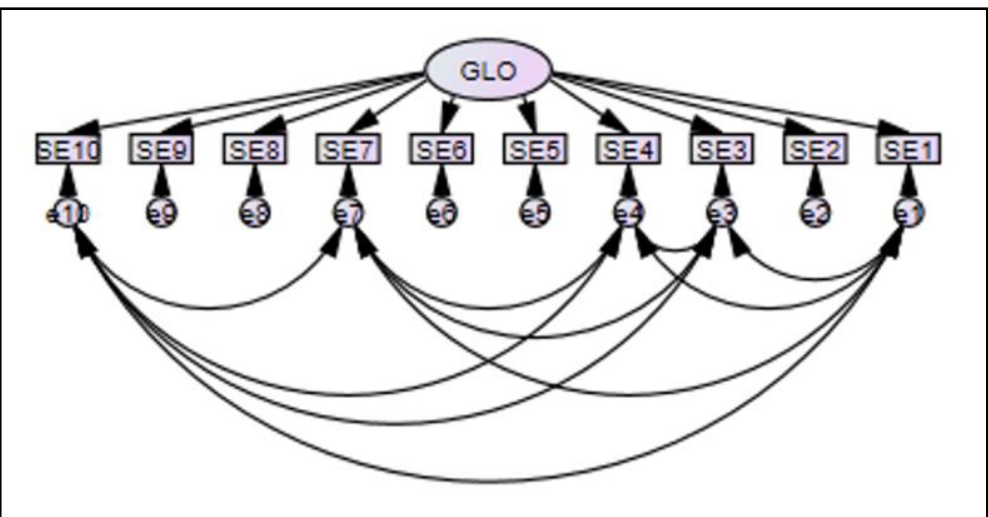

Figure 3: Uni-dimensional positive wording of RSES

Table 4: Covariances: (Group number 1 - Default model)

\begin{tabular}{|c|c|c|c|c|c|c|c|}
\hline & & & Estimate & S.E. & C.R. & P & Label \\
\hline $\mathrm{e} 1$ & $<-->$ & $\mathrm{e} 3$ & .219 & .044 & 4.966 & $* * *$ & \\
\hline $\mathrm{e} 1$ & $<-->$ & $\mathrm{e} 4$ & .132 & .049 & 2.689 & .007 & \\
\hline $\mathrm{e} 1$ & $<-->$ & $\mathrm{e} 7$ & .105 & .048 & 2.162 & .031 & \\
\hline $\mathrm{e} 1$ & $<-->$ & $\mathrm{e} 10$ & -.082 & .046 & -1.792 & .073 & \\
\hline $\mathrm{e} 3$ & $<-->$ & $\mathrm{e} 4$ & .146 & .042 & 3.461 & $* * *$ & \\
\hline $\mathrm{e} 3$ & $<-->$ & $\mathrm{e} 7$ & .129 & .042 & 3.096 & .002 & \\
\hline $\mathrm{e} 3$ & $<-->$ & $\mathrm{e} 10$ & .012 & .038 & .304 & .761 & \\
\hline $\mathrm{e} 4$ & $<-->$ & $\mathrm{e} 7$ & .104 & .050 & 2.078 & .038 & \\
\hline $\mathrm{e} 4$ & $<-->$ & $\mathrm{e} 10$ & .002 & .046 & .034 & .972 & \\
\hline $\mathrm{e} 7$ & $<-->$ & $\mathrm{e} 10$ & .063 & .047 & 1.334 & .182 & \\
\hline
\end{tabular}

Finally, a model was run on Positive and Negative wording correlated, the outcomes $(\mathrm{X} 2=79.68 \mathrm{df}=34 \mathrm{CFI}=0.748 \mathrm{NFI}=0.685 \mathrm{RMSEA}=0.114$ SRMR=0.1151 AIC=121.68). this shows the model was a poor fit but the best model between the four models due to the lower AIC values depicted. The following figure 4 illustrates the model.

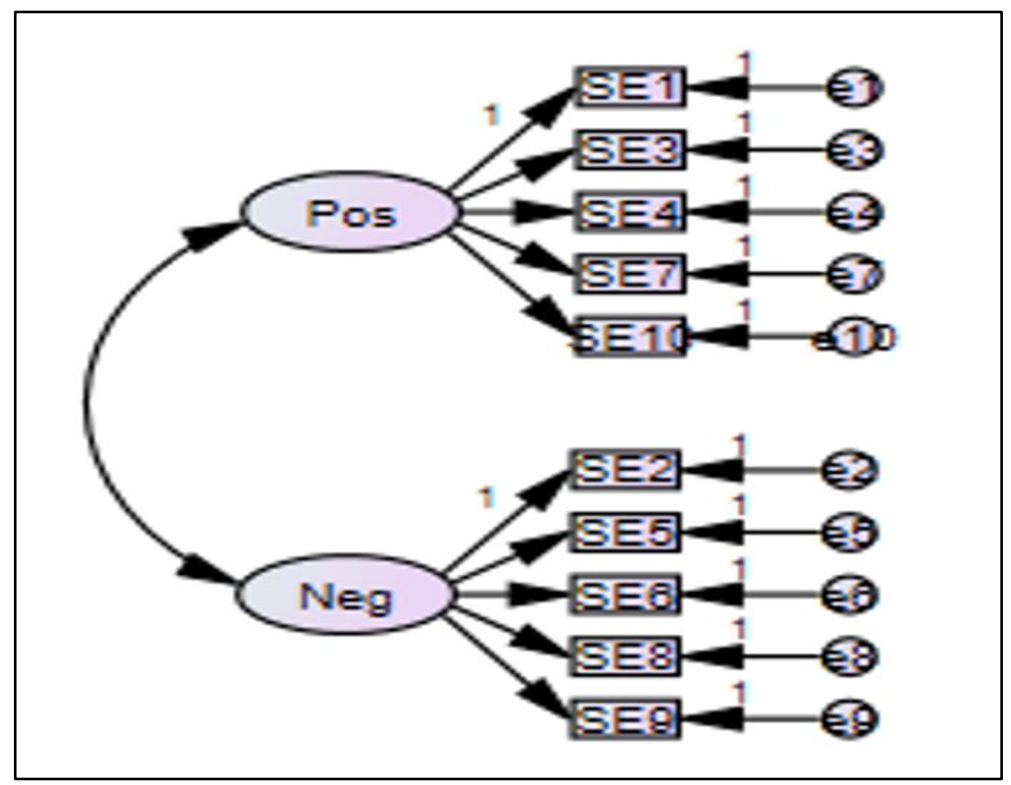

Figure 4: Positive and Negative wording correlated of RSES 
Table 5: Regression Weights: (Group number 1 - Default model)

\begin{tabular}{|c|c|c|c|c|c|c|c|}
\hline & & & Estimate & S.E. & C.R. & P & Label \\
\hline SE1 & $<---$ & Pos & 1.000 & & & & \\
\hline SE3 & $<---$ & Pos & 1.178 & .245 & 4.803 & $* * *$ & \\
\hline SE4 & $<---$ & Pos & .723 & .182 & 3.965 & $* * *$ & \\
\hline SE7 & $<---$ & Pos & .637 & .180 & 3.536 & $* * *$ & \\
\hline SE10 & $<---$ & Pos & .202 & .174 & 1.160 & .246 & \\
\hline SE2 & $<---$ & Neg & 1.000 & & & & \\
\hline SE5 & $<---$ & Neg & -2.421 & .914 & -2.647 & .008 & \\
\hline SE6 & $<---$ & Neg & -4.377 & 1.546 & -2.832 & .005 & \\
\hline SE8 & $<---$ & Neg & -1.293 & .577 & -2.240 & .025 & \\
\hline SE9 & $<---$ & Neg & -2.680 & .946 & -2.833 & .005 & \\
\hline
\end{tabular}

\section{Conclusions}

Following marsh study (1999), nine different CFA models, including the CFA-CTCU and CFA-CTCM models that have been popularized in multitrait-multimethod studies, were employed to test the factorial structure of Rosenberg's self-esteem scale with a sample of injured male rugby players in the Kenya cup competition. The results of the study partially support the findings of Marsh (1996) as every model, including the single-factor model (Model 1), fits data adequately. However, the function of a single theoretical dimension (GSE) was contaminated by method effects. Our results show that method effects need to be taken into account to obtain a close model fit (i.e., RMSEA < 0.05).

Very often, both positively and negatively worded items that measure the same underlying construct are used in psychological rating scales to reduce the response bias brought on by acquiescence (Marsh, 1996). Due to the influence of item wording, participants are often likely to respond - to some extent - to rating items independent of item content. It is thought that negative items on personality, attitude, and other selfconcept rating scale instruments are more likely, compared with positive items, to produce method effects as these items may invoke a double negative logic that causes response bias (Marsh, 1986, 1996). However, our findings suggest that method effects are not necessarily limited to negatively worded items.

In contrast to the findings of Marsh (1996), our results indicate that positively worded questions impose a primary method effect among responses to Rosenberg's selfesteem scale by injured male rugby players in the Kenya cup competition. It is possible that method effects may be caused not only by verbal ability, but also by psychological feelings that the respondents have toward an instrument.

\section{Recommendations}

Several limitations apply to the results of this study. First, the sample used for the study was not a random sample. Although the targeted sampling strategy was used in this study, the generalizability of the results is limited. Second, measures of Rosenberg's self- 
esteem scale were collected via self-administered questionnaires. Perhaps the method of instrument administration makes a difference. For example, it is possible that respondents may attempt to appear more accepting of themselves than they really are in order not to "lose face" when directly interacting with a member of the technical bench or the researcher.

Given the role that self-esteem may play in return to play and recovery of injured male rugby players in the Kenya cup competition (Vergeer, 2006; Walker \& Thatcher, 2011), more studies are needed to better understand the factorial structure of Rosenberg's self-esteem scale as it applies to Injured male rugby players undergoing psychosocial changes after the occurrence of injuries.

\section{Ethics Approval}

Ethical clearance was obtained from Masinde Muliro University of Science and Technology Ethics Committee.

\section{Competing Interest}

The authors declare that they have no competing interests.

\section{Authors \& Contributions}

Anthony Muchiri conceived, designed and performed the study. Prof Edwin Wamukoya and Dr. Donald Kokonya reviewed the manuscript. All authors read and approved the final manuscript.

\section{Disclaimer}

The findings and conclusions presented in this manuscript are those of the authors and do not necessarily reflect the official position of Masinde Muliro University.

\section{Conflict of Interest Statement}

The authors declare no conflicts of interests.

\section{About the Authors}

Anthony Muchiri is a researcher of the department of health promotion and sports science. His research interests are in sports sciences especially performance related and sports psychology.

Edwin Kadima Wamukoya is senior professor and the current dean school of public health and biomedical sciences Masinde Muliro university, he has a diverse experience in research and his current interests are in sports science and performance.

Donald Kokonya is a senior lecturer and the current dean of the school of medicine his current researches interests are in the areas of psychiatry, behavioral science and sports science. 


\section{References}

Marsh, H. M. (1993). Academic self-concept: Theory, measurement, and research. In J. Suls (Ed.), Psychological

Marsh, H. M. (1996). Positive and negative global self-esteem: A substantial meaningful distinction or artifactors? Journal of Personality and Social Psychology, 70, 810819.

Marsh, H. W. (1986). The bias of negatively worded items in rating scales for young children: A cognitive- developmental phenomenon. Developmental Psychology, $22,37-49$.

Mruk, J. C. (1999). Self-esteem: Research, theory, and practice (2nd ed.). New York: Springer.

Pelham, B. W., \& Swann, W. B. (1989). From self-conception to self-worth: On the sources and structure of global self-esteem. Journal of Personality and Social Psychology, 57, 672-680

Rosenberg, M. (1979). Conceiving the self. New York: Basic Books.

Rosenberg, M., Schoenbach, C., Schooler, C., \& Rosenberg, F. (1995). American Sociological Review, 60, 141-156

Patrick W. C. Lau, Mike W. L. Cheung \& Lynda Ransdell (2007) Sports identity and sport participation: A cultural comparison between Collective and Individualistic Societies, International Journal of Sport and Exercise Psychology, 5:1, 66-81, DOI: 10.1080/1612197X.2008.9671813.

Steiger J. H. (2007). Understanding the limitations of global fit assessment in structural equation modeling. Pers Indiv Differ. 2007;42(5): 893-898.

Yu, C. Y. (2002). Evaluating Cutoff Criteria of Model Fit Indices for Latent Variable Models with Binary and Continuous Outcomes [doctoral dissertation]. Los Angeles, CA: University of California.

Vergeer, I. (2006). Exploring the mental representation of athletic injury: A longitudinal case study. Psychology of Sport and Exercise, 7(1), 99-114. https://doi.org/10.1016/j.psychsport.2005.07.003

Walker, N., \& Thatcher, J. (2011). The emotional response to athletic injury: Re-injury anxiety. In J. Thatcher, M. Jones, \& D. Lavallee (Eds.), Coping and emotion in sport (2nd ed., pp. 236-260). New York, NY: Routledge. 


\section{Appendix}

Rosenberg's (1965) Self-Esteem Items (Measured as a 4-point Likert Scale Ranging From 1 [strongly disagree] to 4 [strongly agree])

1. I feel that I ama person of worth at least on an equal basis with others (SE1).

2. I feel that I have a number of good qualities (SE2).

3. All in all, I am inclined to feel that I am a failure (SE3).

4. I am able to do things as well as most other people (SE4).

5. I feel I do not have much to be proud of (SE5).

6. I take a positive attitude toward myself (SE6).

7. On the whole, I am satisfied with myself (SE7).

8. I wish I could have more respect for myself (SE8).

9. I certainly feel useless at times (SE9).

10. At times I think I am no good at all (SE10). 
Anthony Muchiri, Edwin K. Wamukoya, Donald Kokonya

FACTORIAL STRUCTURE OF ROSENBERG'S SELF-ESTEEM SCALE

AMONG INJURED MALE RUGBY PLAYERS IN THE KENYA CUP COMPETITION

Creative Commons licensing terms

Authors will retain the copyright of their published articles agreeing that a Creative Commons Attribution 4.0 International License (CC BY 4.0 ) terms will be applied to their work. Under the terms of this license, no permission is required from the author(s) or publisher for members of the community to copy, distribute, transmit or adapt the article content, providing a proper, prominent and unambiguous attribution to the authors in a manner that makes clear that the materials are being reused under permission of a Creative Commons License. Views, opinions and conclusions expressed in this research article are views, opinions and conclusions of the author(s). Open Access Publishing Group and European Journal of Physical Education and Sport Science shall not be responsible or answerable for any loss, damage or liability caused in relation to/arising out of conflict of interests, copyright violations and inappropriate or inaccurate use of any kind content related or integrated on the research work. All the published works are meeting the Open Access Publishing requirements and can be freely accessed, shared, modified, distributed and used in educational, commercial and non-commercial purposes under a Creative Commons attribution 4.0 International License (CC BY 4.0). 